Fourth International Conference on Sustainable Construction Materials and Technologies http://www.claisse.info/Proceedings.htm

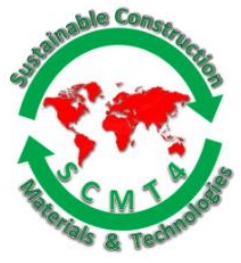

SCMT4

Las Vegas, USA, August7-11, 2016

\title{
Full Scale Corrosion Test on Buried Cast Iron Pipes
}

\author{
Wang.W.G ${ }^{1 \mathrm{a}}$, Li. C.Q ${ }^{1 \mathrm{~b}}$, Robert. D.J. ${ }^{1 \mathrm{c}}$, Zhou. $\mathrm{A}^{1 \mathrm{~d}}$, and M. Wasim ${ }^{1 \mathrm{e}}$ \\ ${ }^{1}$ School of Civil Envir. \& Chem. Eng. RMIT University, GPO. Box 2476, Melbourne Central, Vic 3001, \\ Australia. ${ }^{1 a}$ Email: <s3468547@student.rmit.edu.au>, ${ }^{1 b}$ Email:<chunqing.li@rmit.edu.au>, \\ ${ }^{I c}$ Email:<dilan.robert@rmit.edu.au>, ${ }^{1 d}$ Email: $<$ annan.zhou@rmit.edu.au >, \\ ${ }^{1 e}$ Email:<s3442859@student.rmit.edu.au>.
}

\begin{abstract}
Underground metal pipes are essential infrastructure for water and energy transport. Although the life expectancy of cast iron pipes can exceed one hundred years, the failures of cast iron pipelines often occur unexpectedly as the corrosion causes material deterioration, which induces that the actual service life of pipeline greatly less than the design life expectancy. A systematic research program has been developed to investigate the effect of corrosion on material deterioration of pipelines buried in soil, which are essential for accurate prediction of life expectancy. The details of apparatus, test preparation, corrosion monitoring and measurements are presented in this paper. The research methodology shows effective outcomes for monitoring and evaluating corrosion of metal pipes buried in realistic fine grained soil medium. The current research provides useful knowledge for engineers and asset managers to make maintenance strategies for corrosion affected cast iron pipelines.
\end{abstract}

\section{INTRODUCTION}

Cast iron pipes have had historic use for water and energy transmission since the early 19th century. Due to the widespread use of cast iron pipes in present industries, it is difficult to replace them with new materials at once (Conlin 1991; Sancy et al. 2010). In Australia, there are about 210,000km of buried pipes (Cole, I \& Marney, D 2012) with cast iron pipes representing a significant proportion of ageing pipelines (Petersen \& Melchers 2012). However, the cast iron pipes deteriorate with the increase of service time and, as a result, there are increasing number of failures in present times, causing great economic loss and social impact.

Corrosion has been well known as a main cause of deterioration of cast iron pipes, resulting in either decrease of effective wall thickness or increase in stress concentration. Although corrosion of pipes has been widely investigated, it is found (Mohebbi \& Li 2011; R.B. Petersen 2013) that corrosion of cast iron pipe experiences different rates within service life, imposing difficulties in the prediction of failure events. This is further complicated by underground conditions where both the chemical agents and physical structure (i.e. gas, liquid and solid phases) are involved (Sancy et al. 2010). The corrosion in the underground cast iron pipes is normally dominated by pitting corrosion as a result of the formation of 
aeration cells. The localized/pitting corrosion is thought to be the most hazardous type for the pipe as it requires minimum mass loss while causing direct failure in form of either leakage or crack. Therefore, in order to accurately predict the failure process and make proper maintenance/repair strategies, the corrosion behavior and deterioration mechanisms of burial cast iron pipes need to be investigated thoroughly.

Several studies have been conducted to determine the effects of several influencing factors. For example, Liu ((Liu et al. 2010) investigated the effect of soil compositions ( $\mathrm{Ca} 2+, \mathrm{K}+, \mathrm{SO} 42-, \mathrm{HCO} 3-$, and NO3-) and(WuLiuSun, et al. 2010) investigated the effect of soil $\mathrm{pH}(3,4,5.5$ and 7) on corrosion behavior of metal pipes based on soil simulated soil solutions. The effect of quantity transfer of dissolved oxygen and temperature on corrosion was highlighted based on the work of Nie (Nie, X et al. 2009). However, in most cases, electrochemical parameters derived from soil solution tests were observed differently when compared to field corrosivity tests (Ferreira et al. 2007) and hence, the relevance of simulated soil solution tests to replicate the real service soils condition still remains uncertain(Cole, IS \& Marney, D 2012).

Furthermore, most of previous studies conducted for investigating the metal corrosion (Bell, Moore \& Solis 2010; Liu et al. 2010; Nie, XH et al. 2009; Sancy et al. 2010; WuLiuLuo, et al. 2010) were on the basis of short period of time, e.g. a couple of hours, days or weeks. Only limited laboratory experiments were performed in the corrosion of cast iron with a relatively long exposure time of corrosion ( $<2$ years) e.g.(Goodman 2013; Gupta \& Gupta 1979; Mohebbi \& Li 2011). As a consequence, the data of corrosion mechanism of burial cast iron pipes with multiple corrosion controlling stages as observed in (Petersen \& Melchers 2012; Romanoff 1964) is limited. Also, it is well known that the corrosion behavior of buried pipe may be different from such small specimens as metal plates or coupons due to the effects of specimen geometry and the variance of oxygen access to soil between the top and the bottom of pipe, resulting in non-uniform distribution of corrosion current. Hence, this research aims to investigate the corrosion of full scale cast iron pipes, including the mechanical degradation of the material induced by corrosion. The current study presents the testing methodology and its effectiveness in obtaining the corrosion rates of cast iron pipes.

\section{TESTING METHODOLOGY}

A systematic research program has been developed to investigate the corrosion influencing factors and deterioration mechanism of metal pipes buried in soil. The testing program comprises of corrosion and mechanical tests on coupons and pipe sections having similar material compositions and thicknesses with a failed exhumed pipe obtained from a local water utility. The methodology for testing on metal coupons is presented elsewhere (W. Muhammad 2016). The current testing methodology focusses on the corrosion tests on pipe sections to investigate the corrosion and deterioration of metal pipes under controlled conditions. These controlled conditions include soil moisture content, $\mathrm{pH}$, density, temperature and humidity of environment. The corrosion process was accelerated in the current tests by use of aggressive soil medium since the metal corrosion in most of exposure environments is reported to be a significantly slow process(Romanoff 1957; Rossum, J. R. 1969; Rossum, John R 1969). The corrosion of the cast iron pipes were assessed within such controlled conditions using LPR measurements, 3D scanning method and mass loss method. Subsequently, a series of mechanical tests are planned on corroded pipe sections to investigate the material deterioration. The design and set up information of experiment are presented in subsequent sections.

\section{Materials}

Cast iron pipe sections with outside diameter (OD) $122 \mathrm{~mm}$ and $11 \mathrm{~mm}$ in thickness were used in this 
study. The pipe sections were manufactured with same geometry and material grade, equivalent to a failed exhumed pipe obtained from a local water utility. Vertically pit casting method was used to minimize the wall thickness variance. A total of 18 sections with each $100 \mathrm{~mm}$ in length were used as samples for the corrosion tests. The compositions of new manufactured pipe (No.1\&No3) and exhumed pipes (No.2) are shown in the table 1. Based on the material compositions, the pipe material can be categorized as AS1830 T220 cast iron.

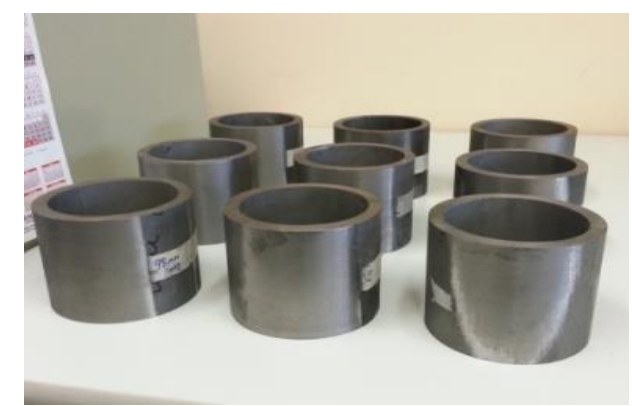

(a)

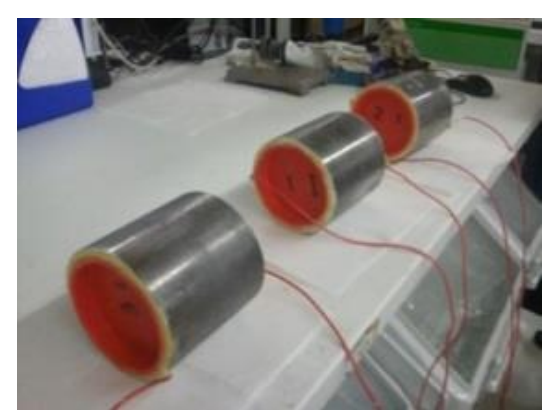

(b)

Figure 1. Pit casting of new pipe (a), Inner surface protection of pipe(b)

Table 1. Composition of the Cast Iron

\begin{tabular}{|c|c|c|c|c|c|c|c|c|c|}
\hline No. & $\mathrm{Fe}$ & $\mathrm{C}$ & $\mathrm{Si}$ & $\mathrm{Mn}$ & $\mathrm{Mg}$ & $\mathrm{Mo}$ & $\mathrm{Al}$ & $\mathrm{P}$ & $\mathrm{S}$ \\
\hline 1 & $\sim \mathrm{BAL}$ & 3.350 & 2.280 & 0.72 & ---- & 0.019 & 0.008 & 0.001 & 0.005 \\
\hline 2 & $\sim \mathrm{BAl}$ & 3.47 & 2.29 & 0.41 & $<0.01$ & 0.06 & $<0.01$ & 0.84 & 0.08 \\
\hline 3 & $\sim \mathrm{BAL}$ & 3.380 & 2.220 & 0.750 & ---- & 0.000 & 0.009 & 0.006 & 0.007 \\
\hline
\end{tabular}

Soils with poor aeration, high electrical conductivity and (or) moisture content are recognized as corrosive soils(Kreysa \& Schütze 2008). Clay is expected to be more corrosive than other types of soils(Cole, IS \& Marney, D 2012). In order to represent the realistic corrosive environment for buried pipes, soil excavated from a Melbourne landfilling site was used in the current research program. This soil can be classified as MD (moderately reactive clay) with good drainage in accordance with AS 2870. Particle size distribution shows over $80 \%$ of particles are less than $75 \mathrm{um}$ in dimension. The soil has also been analyzed for its chemical content as summarized in Table 2. It can be seen from the chemical analysis that the concentration of chloride, sulphate, nitrate are below the threshold values(Srikanth et al. $2005)$, i.e. the influence of these chemical agents is insignificant. Further, the soil shows a good conductivity with low concentration of organic matter $(0.26 \%$ by weight), which is beneficial in the present study as the influence of most microorganisms can be eliminated.

Table 2. Chemical Compositions of Soil

\begin{tabular}{|c|c|}
\hline Species & Concentration \\
\hline Chloride & $115.60 \mathrm{mg} / \mathrm{kg}($ or ppm) \\
\hline Sulphate as SO4 & $50.00 \mathrm{mg} / \mathrm{kg}(\mathrm{or} \mathrm{ppm})$ \\
\hline Nitrate NO3 & $23.05 \mathrm{mg} / \mathrm{kg}($ or ppm) \\
\hline Organic Matter & $0.26 \%$ \\
\hline Orignial pH & 8.17 \\
\hline Resistivity & $23.46 \Omega \cdot \mathrm{m}$ \\
\hline
\end{tabular}




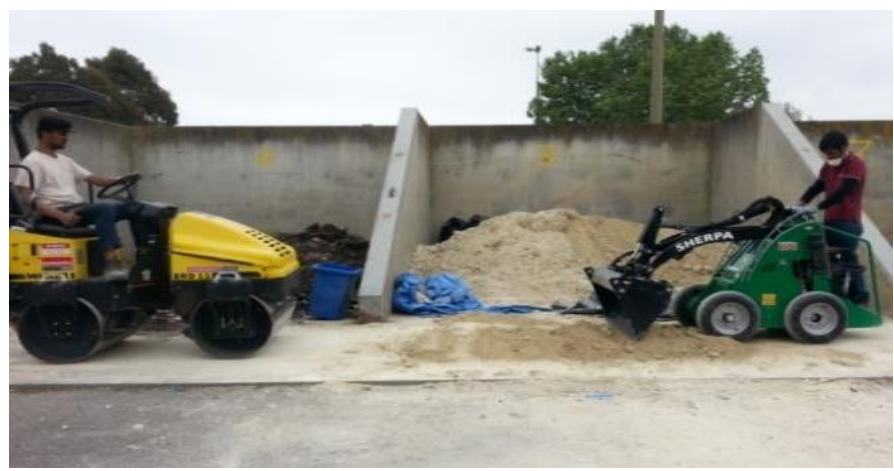

(a)

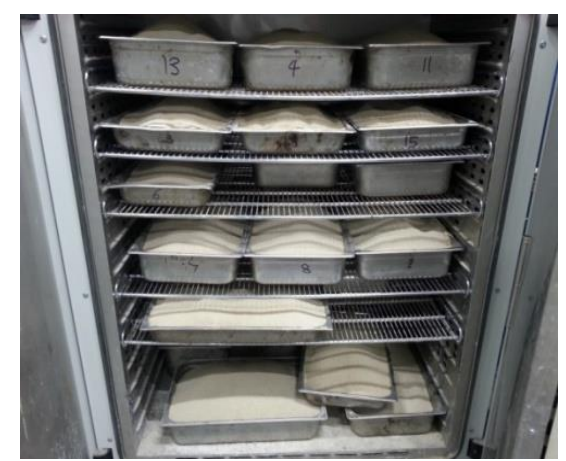

(b)

Figure 2. Soil crashing (a) and oven dry (b)

\section{Exposure condition and time}

Unlike the previous work conducted in this field of research(Goodman 2013; Gupta \& Gupta 1979; Murray \& Moran 1989) where the soil container is either sealed, restricting oxygen diffusion and water transport or allows the water evaporation under room environment while not controlling the saturation, the soil in present study allows the natural oxygen and water diffusion process with controlled saturation throughout the medium. The corrosion and mechanical strength of the pipe sections are expected to be assessed at 6 months internal. The temperature and humidity were controlled in the testing chamber at $24^{\circ} \mathrm{C}$ and $50 \% \mathrm{RH}$ in alignment with AS1012.13 (as shown in Figure 3).

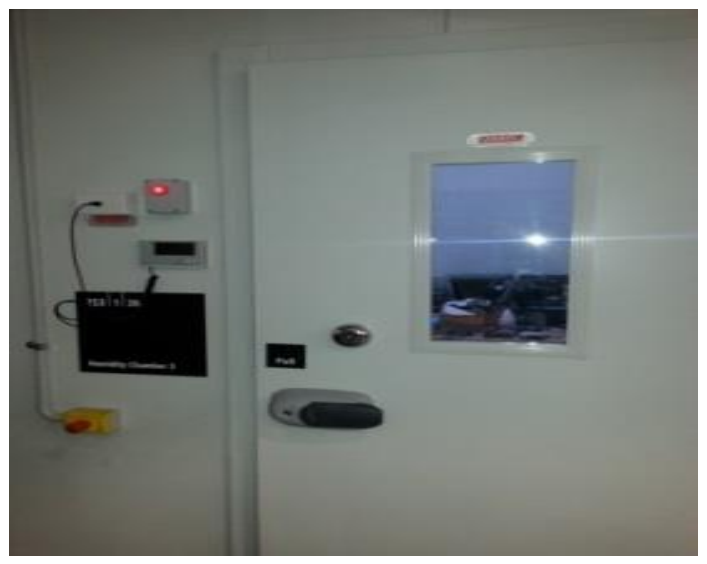

Figure 3. The Environmental Chamber

\section{Soil pH}

The soil $\mathrm{pH}$ in the field usually covers a wide range. For example, the $\mathrm{pH}$ of soils tested by the National Bureau of standards in 128 locations varied from 2.6 to 10.2 (Romanoff 1964). Further, a recent field observation of 18 sites in Australia shows the $\mathrm{pH}$ of soils varies from 4.6 to 8.3 (R.B. Petersen 2013). In the current research, the $\mathrm{pH}$ value of 2.5 and 3.5 were targeted to induce aggressive corrosive environment for accelerating the corrosion. In order to obtain the accurate measurements of diluted acid amounts for target $\mathrm{pH}$, trial tests were conducted following ASTM D D4972. Based on trial test results, the diluted acid (4.6\%) with quantity of 187 grams is required to achieve pH 3.5 for $10 \mathrm{~kg}$ oven dry soil, and 300 grams of diluted acid (4.6\%) was used to reach pH 2.5 in $10 \mathrm{~kg}$ dried soil. 


\section{Saturation}

Previous studies showed that water content of soil can significantly influence the corrosion rates of the metals(Gupta \& Gupta 1979; Murray \& Moran 1989). However, it is ambiguous to identify a soil specific optimal moisture content which corresponds to the highest metal corrosion, mainly due to the fact that this can be dependent on soil dry density. The present research identifies the moisture dependence through saturation term which defines the ratio of water volume to the total void volume in the soil. This term is thought to be unified and reasonable than traditional water content as the dependence of water saturation on density can be captured explicitly. Previous research work(Murray \& Moran 1989) showed that soil could depict aggressive corrosion at the water saturation of $80 \%$. The initial saturation of the present test was also selected as $80 \%$ at the target dry density of $1600 \mathrm{~kg} / \mathrm{m}^{3}$.

\section{Burial depth}

Most of the water pipes in Australia are buried with cover heights of less than $1 \mathrm{~m}$ (Petersen \& Melchers 2012). Previous research work in this field showed that the effective outcomes for metal corrosion can be obtained with cover heights of 300mm(Goodman 2013). On this basis, the cover height for the current studies was selected as $300 \mathrm{~mm}$.

\section{Instruments}

In order to monitor the target initial conditions and metal corrosion, a comprehensive arrangement of instruments was made in the experimental setup.

Saturation: MP 406 moisture sensors were used in present test to monitor the water saturation of clay soil. The working mechanism of sensors is based on dielectric theory where the dielectric permittivity of each fraction in soil is different from another one, with water having unique higher dielectric permittivity (80) than others (e.g. air 1, soil minerals 3-7). The change of volume fraction of water will influence the total dielectric permittivity dramatically. The soil water content, as a result, can be calculated precisely based on the variation of dielectric constant of the soil. The moisture sensor was buried with $50 \mathrm{~mm}$ distance from pipe to avoid the potential influence of electric field of sensor on pipe external surface. In addition, high capacity digital scale was used to determine the total water loss as a result of water evaporation.

$\mathrm{pH}$ and temperature: $\mathrm{pH}$ electrodes with automatic temperature compensation function were buried at the same level of pipe, and the $\mathrm{pH}$ of soil was continuously monitored through Alpha $\mathrm{pH} 500$ controller with $\pm 0.01 \mathrm{pH}$ accuracy. Three thermocouples were used in each container with distance of $30 \mathrm{~mm}$ away from pipe section to monitor the temperature around the specimens (figure 5).

Electrochemical corrosion measurement: LPR measurement has been proved to be a relatively reliable technique in terms of measuring the corrosion rate of underground structures (Gareth Kear 2006). It provides an instantaneous measurement of the polarization resistance of corroding system. However, since only uniform corrosion distribution is assumed based on the measurement mechanism, the localized corrosion may be underestimated. Nevertheless, this technique can serve as a direct and quick indication of corrosion rate and potential of corroding metal. In present study, ACM field system was used for LPR and Ecorr measurement. The measurement was performed on a three electrode system, i.e. working electrode, reference electrode and counter electrode, with pipe section serve as working electrode of the electrochemical cell. The compensation technique was used to eliminate the effect of soil medium. The scanning range of linear polarization was $\pm 30 \mathrm{mV}$. 


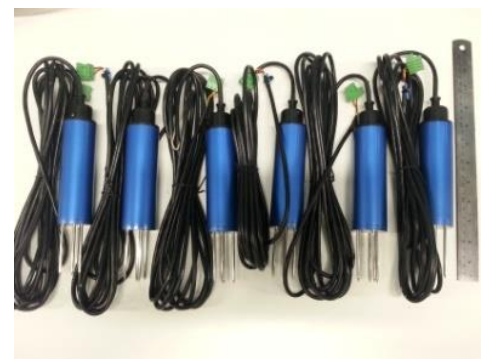

(a)

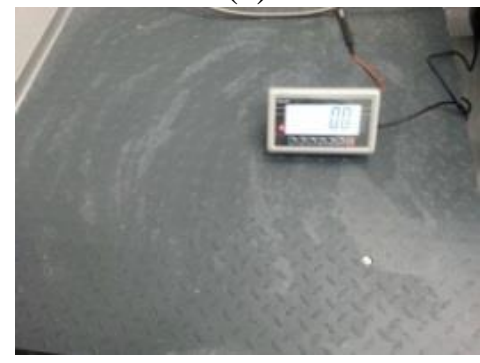

(c)

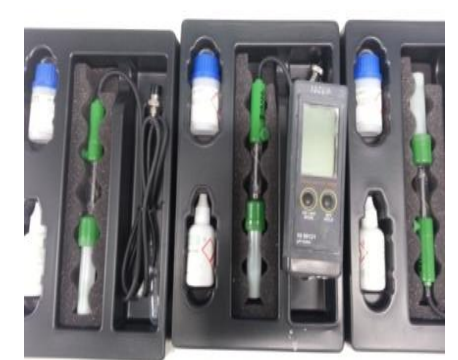

(b)

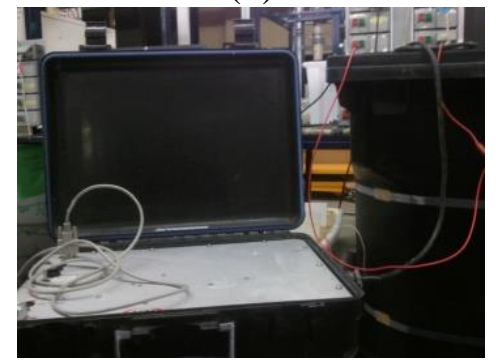

(d)

Figure 4. pH sensor (a), MP 406 moisture sensor (b) high capacity scale(c) and LPR kit (d)

\section{Experiment set up}

As the soil received from the field was consisted in the form of big lumps, it was crushed to uniform size by crusher (figure 2 (a)) and further sieved using BS 410 having aperture size of $2.36 \mathrm{~mm}$. Having the soil been oven dried (figure 2 (b), it was mixed with diluted acid to reach $\mathrm{pH}$ with 2.5 and 3.5, respectively.

The external walls of cast iron pipe sections were polished by use of lathe to obtain smooth external surface with a nominal thickness of $11 \mathrm{~mm}$ (figure 1 (a)). The dimensions of pipe sections were measured by use of both $3 \mathrm{D}$ scanner and digital caliper ruler. Having measured the dimensions, the pipe samples were weighed to obtain the initial mass of the sections. Then, the inner surface of pipe was painted with epoxy to restrain internal corrosion (i.e. to induce only outside pipe wall corrosion). Also, polyethylene caps were used to seal the ends of pipe sections (figure 1 (b)) and the copper wires were connected with pipe section at the ends for electrochemical corrosion measurement purpose (as seen in figure 5 (a)).

In order to eliminate the influence of wall boundary on the metal corrosion, the geometry of soil container and pipe were designed so that a circle with the distance from pipe surface to both walls and bottom of the container to be same as the burial depth (i.e. $300 \mathrm{~mm}$ ) as showed in figure 5 (b). Three pipe sections were buried in one container with half a diameter space between them (i.e. $60 \mathrm{~mm}$ ). Firstly, a bedding layer was prepared in the container with $300 \mathrm{~mm}$ height at the target dry density. Then the pipe sections, which were coated on all the sides except the outer surface, were placed on the bedding layer. This simulates the real corrosive environment for the external pipe wall of the buried pipes. Having placed the pipe sections, the test box was divided into three compartments to minimize the disturbance to the soil and pipes during the pipe sample removal for mechanical testing. After internal separation of the container, the compartments were filled with measured amount of soil with uniform compaction to maintain homogeneity in the soil while achieving the target initial condition of the tests. The hi-swell bentonite soil was used as the interface between the test soil and container wall since the possibility of gap formation between the clay soil and the container wall during water evaporation. The detailed initial conditions of the experiment presented in this work are showed in table 3. 
Table 3. Initial Conditions of the Test

\begin{tabular}{|c|c|}
\hline Initial Test Condition & Value \\
\hline Soil pH & $2.5,3.5$ \\
\hline Saturation & $80 \%$ \\
\hline Burial depth & $300 \mathrm{~mm}$ \\
\hline Soil dry density & $1600 \mathrm{~kg} / \mathrm{m} 3$ \\
\hline Ambient humidity & $50 \% \mathrm{RH}$ \\
\hline Ambient Temperature & $16-22 \& 24$ Celsius \\
\hline
\end{tabular}
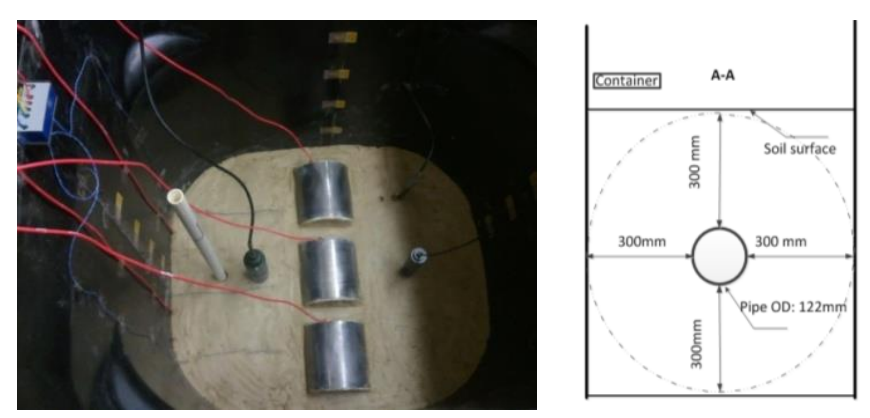

\section{Figure 5. Test Setup for Sepcimens in Clay Soil}

\section{OBSERVATION AND DISCUSSIONS}

\section{Monitoring and controlling of initial conditions}

The observed moisture contents of the soil at the surface and the pipe level are showed in figure 6 for the current test duration (i.e. 135 days). It can been seen that the moisture content at pipe burial level was stable at 20\%, whereas the moisture level at the top surface fluctuated due to evaporation and external addition of water. The addition of water was based on the mass loss measured from the high capacity scale. The monitored moisture content readings revealed that the current testing methodology is effective to maintain uniform moisture content throughout the test duration.

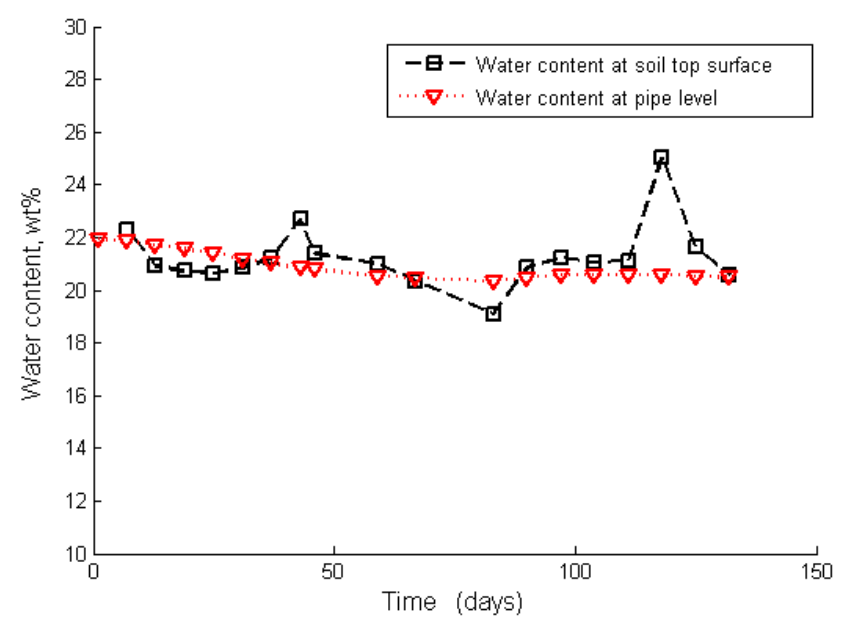

Figure 6. Moisture content of the soil at the surface of soil and burial level of pipe 
The $\mathrm{pH}$ and temperature variations of the soil at the pipe level were also monitored during the test as showed in figure 7 and 8 respectively. It can be seen that the $\mathrm{pH}$ readings of soil were held constant at 3.5 during the last 135 days. The readings from the thermometers also showed consistency with a slight variation $\left(18^{\circ} \mathrm{C}\right.$ to $\left.20^{\circ} \mathrm{C}\right)$ due to change in the temperature of the environment.

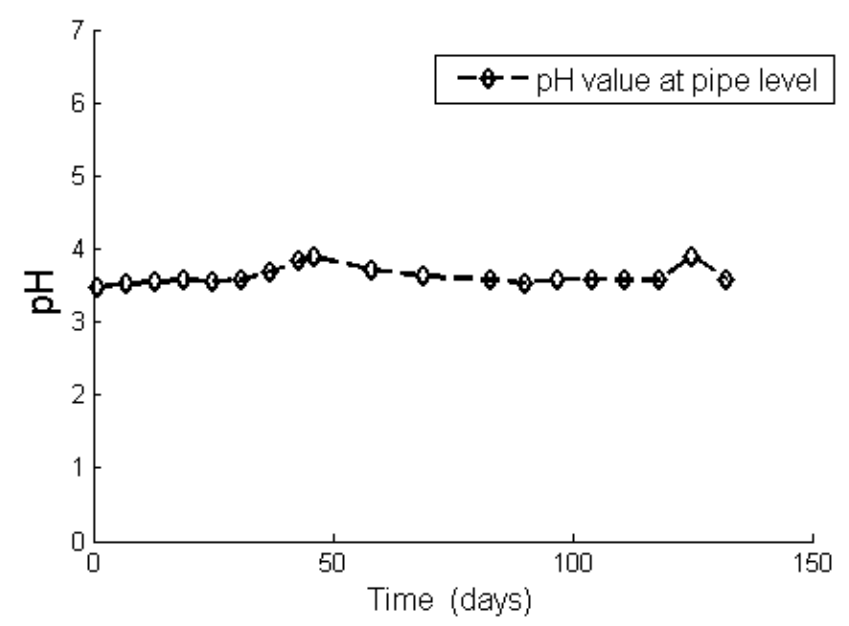

Figure 7.pH of soil at pipe burial level

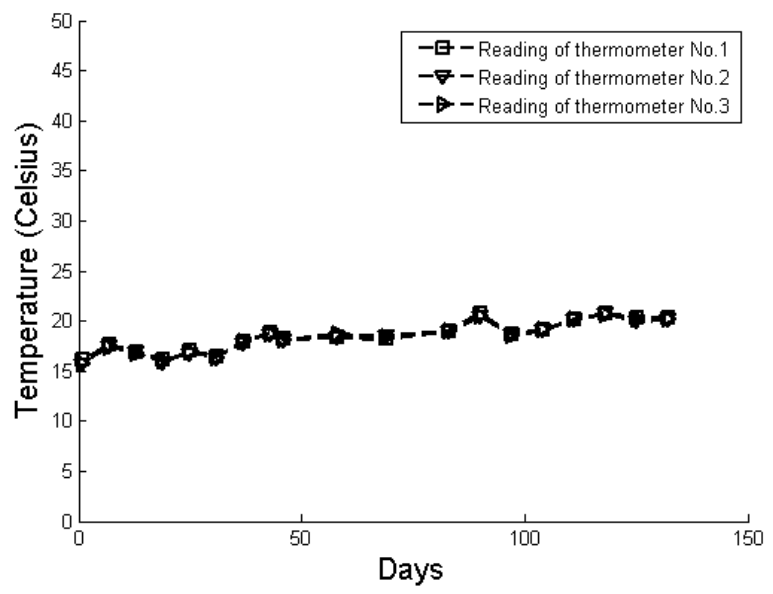

Figure 8.The temperature recorded by thermometers 1-3

\section{Corrosion of metal pipe}

The corrosion reaction activities were recorded throughout the experiment using E corr measurements (figure 9). The potential values of the pipe sections showed an initial value of $-730 \mathrm{mV}$ at the first day after setting up the experiment, which is consistent with the initial potential value observed in small scale coupon test (W. Muhammad 2016). The values dropped immediately lower than $-740 \mathrm{mV}$, and the period of more negative potential values lasted one month with some fluctuations at the end of the first week. Subsequently, the potential moved towards positive until reaching a peak of $-660 \mathrm{mV}$. Finally, the potential dropped again and stabilized at more negative values. This is because the soil was initially rich in oxygen which caused to form a passive film on the external surface of pipe. After the oxygen in the soil has been consumed, the weakening of passive film by acid condition started to dominate the corrosion behavior. 


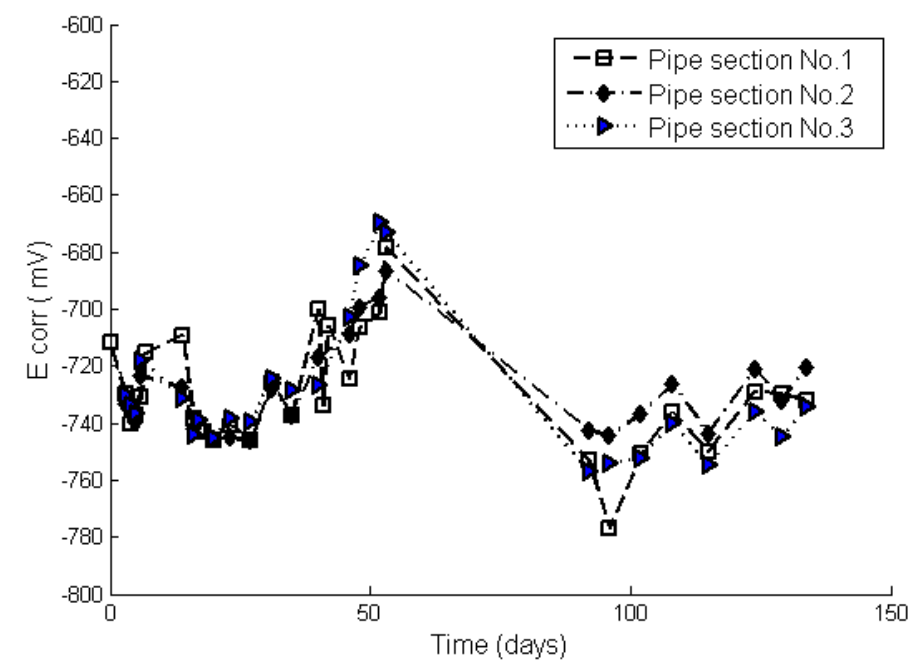

Figure 9. E corr value for pipe sections 1-3

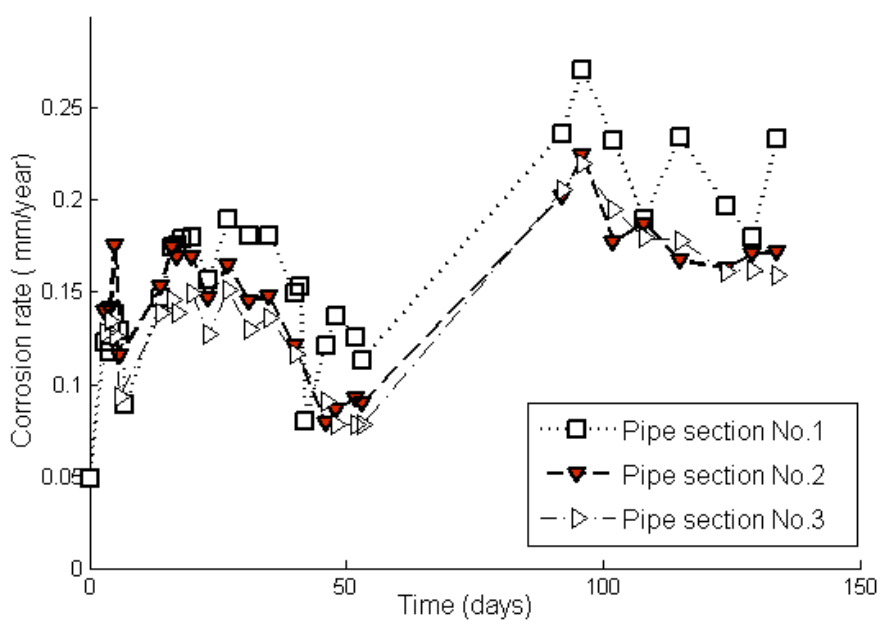

Figure 10.Corrosion rate/ penetration $(\mathrm{mm} / \mathrm{year})$ for pipe sections 1-3

The corrosion current was assessed for the buried pipes based on polarization resistance (Fig 10). In general, the corrosion rates in three pipe sections were consistent, showing a two-stage corrosion process in its evolution. An initial corrosion rate of $0.06 \mathrm{~mm} /$ year was observed in pipe section No. 1 . It showed an increasing trend of corrosion rate from initial value to around $0.2 \mathrm{~mm} /$ year within the duration of the first 30 days. Then the corrosion rate slowly decreased to a small value (i.e. $0.07 \mathrm{~mm} /$ year) after 50 days duration before the corrosion rate experienced the second increasing trend. The second stage of corrosion rate peaked to $0.28 \mathrm{~mm} /$ year after about 100 days of corrosion and stabilized subsequently at approximate $0.2 \mathrm{~mm} /$ year. Such trend of corrosion rate evolution can be explained in conjunction with the forming/weakening of the passive film around the metal surface. The corrosion rate decreased initially due to the formation of the passive film which was indicated by the metal potential moving towards more positive value. As a result of the weakening of passive film by acid environment, the corrosion rate leveled at a relatively high rate. 


\section{CONCLUSION}

The current research presents a methodology to investigate the effects of factors influencing external corrosion of buried metal pipes. The developed method showed effective outcomes for evaluating the corrosion of buried cast iron pipes in the controlled environments of density, moisture, $\mathrm{pH}$ and temperature. The result revealed that the pipes buried in soil experienced different corrosion rates with a general two stage corrosion as observed in previous studies. Further, it was observed that electrochemical measurement technique (LPR) used in present research can provide direct and instantaneous information of corroding buried pipes. The research is currently extending for further evaluations of pipe corrosion under multiple variables, coupling with the mechanical performance of the corroded materials. It is expected that the outcomes of this research will be highly useful for the industry and buried pipes asset managers for better understanding of corrosion rates which can facilitate effective maintenance strategies.

\section{ACKNOWLEDGEMENTS}

Financial support from Australian Research Council under DP140101547 and LP150100413 is gratefully acknowledged.

\section{REFEREMCES}

Bell, J, Moore, C \& Solis, L 2010, 'Laboratory Investigations of Corrosion Mechanisms and Control for Ductile Iron Pipe in Simulated Polyethylene Encasement (AWWA C105)', paper presented to Pipelines 2010@sClimbing New Peaks to Infrastructure Reliability: Renew, Rehab, and Reinvest.

Cole, I \& Marney, D 2012, 'The science of pipe corrosion: A review of the literature on the corrosion of ferrous metals in soils', Corrosion Science, vol. 56, pp. 5-16.

Cole, IS \& Marney, D 2012, 'The science of pipe corrosion: A review of the literature on the corrosion of ferrous metals in soils', Corrosion Science, vol. 56, pp. 5-16.

Conlin, RM, and T. J. Baker 1991, Application of fracture mechanics to the failure behaviour of buried cast iron mains.

Ferreira, CAM, Ponciano, JA, Vaitsman, DS \& Pérez, DV 2007, 'Evaluation of the corrosivity of the soil through its chemical composition', Science of the Total Environment, vol. 388, no. 1, pp. 250-5.

Gareth Kear, IFaSJ 2006, 'Application of polarisation resistance measurements for the estimation of corrosion rates of galvanised steel structures in soils', Grand Chancellor Hotel, Hobart Australia, 1922 November

Goodman, NM, Tim et al.. 2013, Accelerated test based on EIS to predict buried steel pipe corrosion, Brisbane Convention and Exhibition Centre.

Gupta, S \& Gupta, B 1979, 'The critical soil moisture content in the underground corrosion of mild steel', Corrosion Science, vol. 19, no. 3, pp. 171-8.

Kreysa, G \& Schütze, M 2008, DECHEMA corrosion handbook, Dechema. 
Liu, TM, Wu, YH, Luo, SX \& Sun, C 2010, 'Effect of soil compositions on the electrochemical corrosion behavior of carbon steel in simulated soil solution', Materialwissenschaft Und Werkstofftechnik, vol. 41, no. 4, pp. 228-33.

Mohebbi, H \& Li, C 2011, 'Experimental investigation on corrosion of cast iron pipes', International Journal of Corrosion, vol. 2011.

Murray, JN \& Moran, PJ 1989, 'Influence of Moisture On Corrosion Of Pipeline Steel In Soils Using Insitu Impedance Spectroscopy', Corrosion, vol. 45, no. 1, pp. 34-43.

Nie, X, Li, X, Du, C \& Cheng, Y 2009, 'Temperature dependence of the electrochemical corrosion characteristics of carbon steel in a salty soil', Journal of Applied Electrochemistry, vol. 39, no. 2, pp. 277-82.

Nie, XH, Li, XG, Du, CW \& Cheng, YF 2009, 'Temperature dependence of the electrochemical corrosion characteristics of carbon steel in a salty soil', Journal of Applied Electrochemistry, vol. 39, no. 2, pp. 277-82.

Petersen, R \& Melchers, R 2012, 'Long-Term Corrosion of Cast Iron Cement Lined Pipes', Corrosion and Prevention, pp. 11-4.

R.B. Petersen, MD, R.E. Melchers 2013, 'Modelling the lone-term corrosion of cast iron pipes', Corrosion and Prevention.

Romanoff, M 1957, Underground corrosion, US Government Printing Office.

---- 1964, 'Exterior corrosion of cast-iron pipe', Journal (American Water Works Association), pp. 112943.

Rossum, JR 1969, 'Prediction of pitting rates in ferrous metals from soil parameters', Journal (American Water Works Association), pp. 305-10.

Sancy, M, Gourbeyre, Y, Sutter, EMM \& Tribollet, B 2010, 'Mechanism of corrosion of cast iron covered by aged corrosion products: Application of electrochemical impedance spectrometry', Corrosion Science, vol. 52, no. 4, pp. 1222-7.

Srikanth, S, Sankaranarayanan, TSN, Gopalakrishna, K, Narasimhan, BRV, Das, TVK \& Das, SK 2005, 'Corrosion in a buried pressurised water pipeline', Engineering Failure Analysis, vol. 12, no. 4, pp. 634-51.

W. Muhammad, CQLaDJR 2016, 'Experimental Investigation Of Factors Influencing External Corrosion Of Buried Pipes.', paper presented to Proceedings of the 4th Conference on Sustainable Construction Materials and Technologies Las Vegas, USA, August 7- 11, 2016.

Wu, YH, Liu, TM, Luo, SX \& Sun, C 2010, 'Corrosion characteristics of Q235 steel in simulated Yingtan soil solutions', Materialwissenschaft Und Werkstofftechnik, vol. 41, no. 3, pp. 142-6.

Wu, YH, Liu, TM, Sun, C, Xu, J \& Yu, CK 2010, 'Effects of simulated acid rain on corrosion behaviour of Q235 steel in acidic soil', Corrosion Engineering Science and Technology, vol. 45, no. 2, pp. 13641. 